\title{
PROFESSORES COORDENADORES SOB O OLHAR DOS PROFESSORES
}

\section{COORDINATOR TEACHERS UNDER THE TEACHER'S VIEW}

\author{
PROFESORES COORDINADORES BAJO \\ LA MIRADA DE LOS PROFESORES
}

Luciane Aparecida de Oliveira ${ }^{1}$

Laura Noemi Chaluh ${ }^{2}$

${ }^{1}$ Secretaria Municipal de Educação da Prefeitura de Rio Claro, Rio Claro/SP- Brasil ${ }^{2}$ Universidade Estadual Paulista "Júlio de Mesquita” (UNESP), Rio Claro/SP- Brasil

Resumo Neste trabalho socializamos recorte de uma pesquisa que objetivou compreender a constituição dos professores coordenadores e da coordenadora pedagógica, considerando suas atribuições (administrativas e pedagógicas) e as relações que estabelecem com a comunidade escolar (gestão, professores, funcionários, alunos e pais) e com a Secretaria Municipal de Educação (SME) de uma cidade do interior do Estado de São Paulo. A pesquisa tematizou os desafios que esses sujeitos enfrentavam e que circulavam no interior de um Grupo de Estudos, sob a responsabilidade da coordenadora pedagógica vinculada à SME. A perspectiva teórico-metodológica assumida foi a pesquisa narrativa. Neste trabalho, socializamos levantamento feito pelos professores coordenadores nas respectivas escolas que dizem das percepções dos professores em relação às atribuições dos primeiros. Explicitamos as lições aprendidas pela coordenadora pedagógica, responsável pelo Grupo de Estudos, que evidenciamos concepções de formação dos professores coordenadores e suas implicações ao pensar nos mesmos enquanto articuladoras da formação no contexto escolar. Para compor o trabalho, trazemos os registros dos professores das escolas e da coordenadora pedagógica. $\mathrm{O}$ trabalho contribui para repensar os processos formativos no contexto de redes de ensino.

Palavras-chave: Professor coordenador; FormaÇão continuada; Rede de ensino,

Abstract In this work, we analyze a snippet of a research that aimed to understand the formation of teachers and pedagogical coordinators, considering their responsibilities (administrative and pedagogical) and the relationships they establish with the school community 
(management, teachers, clerks, students and parents), together with the Municipal Secretary of Education (SME) of a city in the interior of the State of São Paulo. The research focused in the challenges that those subjects faced and were present within a Study Group, under the responsibility of the pedagogical coordinator associated to the SME. The theoretical-methodological perspective assumed was the narrative research. In this work, we share a survey realized by the coordinating teachers in their respective schools and which results report the teachers' perceptions regarding the assignments of the coordinating teachers. We expose the lessons learned by the pedagogical coordinator, in charge of the Study Group, which show the concepts of the formation of coordinating teachers and their implications when thinking about them as articulators of formation in the school context. To compose the work, we bring the records made by the teachers and the pedagogical coordinator. This work contributes to rethink the formative processes in the context of educational networks. Keywords: Coordinating teacher; Continuing education; Educational network.

Resumen En este trabajo socializamos un recorte de una investigación que tuvo como objetivo comprender la constitución de los profesores coordinadores y de la coordinadora pedagógica, considerando sus atribuciones (administrativas y pedagógicas) y las relaciones que establecen con la comunidad escolar (gestión, profesores, funcionarios, alumnos y padres) y con la Secretaría Municipal de Educación (SME) de una ciudad del interior del Estado de San Paulo. La investigación tuvo como tema los desafíos que esos sujetos enfrentaban y que circulaban en el interior de un Grupo de Estudios, cuya responsabilidad era de la coordinadora pedagógica vinculada a la SME. La perspectiva teórico-metodológica sumida fue la investigación narrativa. En este trabajo socializamos el levantamiento hecho por los profesores en relación a las atribuciones de los primeros. Explicitamos las lecciones aprendidas por la coordinadora pedagógica, responsable por el Grupo de Estudios, que dejan en evidencia las concepciones de formación de los profesores coordinadores y sus implicaciones para pensar en ellos como articuladores de la formación en el contexto escolar. Para componer el trabajo, traemos os registros de los profesores de las escuelas y de la coordinadora pedagógica. El trabajo contribuye para repensar los procesos formativos en el contexto de rede de enseñanza.

Palavras clave: Profesor coordinador; Formación continuada; Red de Enseñanza.

\section{INTRODUÇÃo}

O presente trabalho é recorte de uma pesquisa de mestrado (OLIVEIRA, 2016), que socializa parte do percurso de formação desenvolvido com os professores coordenadores ${ }^{1}$ (PCs), da rede de educação, de um município do interior de São Paulo. A primeira autora do

\footnotetext{
Professor eleito pela Equipe Docente e Gestora que, afastado de seu cargo, exerce a função de professor-coordenador na escola, desenvolvendo as seguintes ações: coordenar, acompanhar, avaliar e propor alternativas de solução do processo pedagógico no âmbito da unidade educacional.
} 
trabalho foi Coordenadora Pedagógica ${ }^{2}$ (CP) do Ensino Fundamental, no período de 2009 a 2017, vinculada à Secretaria Municipal de Educação da referida cidade, e fez parte do CAP (Centro de Aperfeiçoamento Pedagógico). Dentre os objetivos do CAP destacamos: coordenar e desenvolver projetos pedagógicos junto à rede municipal de ensino; promover cursos de capacitação e atualização; promover e coordenar eventos que estimulem a sistematização da prática pedagógica dos docentes do sistema municipal de ensino; incentivar e desenvolver pesquisas ligadas à área educacional; buscar assessoria junto a universidades e centros de pesquisa na área da educação; desenvolver ações descentralizadas de formação continuada; promover ações que possibilitem a socialização de experiências pedagógicas bem-sucedidas; organizar grupos de estudo, de acordo com as necessidades da rede escolar e acompanhar o trabalho pedagógico desenvolvido nas escolas. Esses objetivos estão presentes na Lei n. ${ }^{\circ}$ 3706, de 17 de novembro de 2006, que dispõe sobre a regulamentação do CAP.

No ano de 2014, a referida Coordenadora Pedagógica constituiu um Grupo de Estudos e fez convite a todos os professores coordenadores das escolas de Ensino Fundamental, que estavam sob sua orientação, com a intencionalidade de atingir os objetivos definidos pelo CAP, especialmente aqueles que dizem da formação continuada. Ao todo, participaram daquele grupo 32 professores coordenadores.

A pesquisa em questão teve como temática a formação continuada e tomou como objeto de estudo os encontros de formação realizados com o Grupo de Estudos, acima referido, ao longo de 18 meses. O objetivo da pesquisa foi compreender a constituição do professor coordenador no contexto escolar e do coordenador pedagógico, vinculado à Secretaria daquele município, levando em consideração suas atribuições (administrativas e pedagógicas) e as relações que estabeleciam com a comunidade escolar (gestão, professores, funcionários, alunos e pais) e com a Secretaria Municipal de Educação.

A perspectiva teórico-metodológica assumida foi a pesquisa narrativa na concepção de Lima, Geraldi e Geraldi (2015). Os autores identificam quatro perspectivas vinculadas às narrativas: a narrativa como construção de sentidos para um evento; a narrativa (auto) biográfica; a narrativa de experiências planejadas para desenvolver pesquisas e a narrativa de experiência do vivido, ou seja, narrativas de experiências educativas. A pesquisa em questão foi desenvolvida tendo como referência a narrativa de experiência do vivido, pois "havendo uma experiência significativa na vida do sujeito pesquisador, este a toma como objeto de compreensão. Essas pesquisas decorrem de uma situação não experimental, mas vivencial!" (LIMA; GERALDI; GERALDI, 2015, p. 27).

Nessa perspectiva, o pesquisador, também sujeito da pesquisa, narra acontecimentos vividos a partir dos quais é possível extrair lições apresentadas, enquanto conhecimentos produzidos a posteriori, a partir do próprio vivido e narrado. $\mathrm{O}$ diferencial desta

2 O Coordenador Pedagógico, vinculado ao Centro de Aperfeiçoamento Pedagógico, é responsável pelo desenvolvimento do Plano de Trabalho Pedagógico da Secretaria Municipal da Educação, promove cursos de formação continuada, oferece apoio técnico-pedagógico às equipes escolares no processo de elaboração e implementação da Proposta Pedagógica da escola, na elaboração de ações que possibilitem o sucesso na aprendizagem dos alunos e subsidia o trabalho do Professor-Coordenador. 
perspectiva é que o foco está no sujeito e, a partir da experiência educativa, busca extrair lições, no sentido de conselho (BENJAMIN, 1985). Como reflete sobre o fato ocorrido, tal perspectiva contribuiu tanto para a formação profissional de quem narra sua experiência, quanto para a constituição desse sujeito, sendo este o pesquisador. Como considerado por Lima, Geraldi e Geraldi (2015, p. 27), essa perspectiva de pesquisa "Oportuniza aprendizagem de pesquisador ao sujeito/objeto da pesquisa, que aprende a pesquisar no processo e pesquisando aprende mais sobre o exercício de sua profissão de professor e sobre sua própria vida".

Para a interpretação dos dados produzidos na pesquisa, levamos em consideração o paradigma indiciário de Ginzburg (1989). Trata-se de um método interpretativo no qual detalhes que se apresentam, aparentemente, como secundários, são essenciais para ter acesso a determinada realidade. Segundo Ginzburg (1989, p. 145), "o conhecedor de arte é comparável ao detetive que descobre o autor do crime".

$\mathrm{Na}$ investigação narrativa da própria experiência, o trabalho do pesquisador é estudar as situações do vivido e através dela formular hipóteses explicativas. O objetivo é a compreensão dos fenômenos e dos modos de atuar sobre eles. O importante nesse tipo de pesquisa não são os acontecimentos em si, mas sim como utilizá-los de modo a construir pistas e caminhos que permitam ao leitor e ao narrador construir lições nela indiciadas. A percepção do autor é essencial, pois as hipóteses interpretativas não emergem diretamente do dado. Na pesquisa narrativa de experiência não há nada a ser comprovado, mas muito a ser compreendido. É o conjunto que faz a diferença, dados isolados contribuem pouco. Nesse tipo de pesquisa entra em jogo o que Ginzburg (1989) chamou de elementos imponderáveis: faro, golpe de vista, intuição. Cabe ao pesquisador estar atento aos detalhes durante a pesquisa, pois eles são carregados de informações, implícitas, que trazidas à discussão colocam todos os envolvidos em reflexão, sendo estas voltadas à sua prática, à atuação dos docentes e aquilo pelo qual buscamos esclarecimentos.

Neste trabalho, apresentamos uma proposta realizada no Grupo de Estudos, quando a Coordenadora Pedagógica, responsável pela formação daquele grupo, solicitou que cada professor coordenador fizesse uma pesquisa na sua escola com os professores, para que eles respondessem à seguinte questão: "O que esperam do professor coordenador quanto a sua atuação e atribuição da função?" As respostas elaboradas pelos professores das respectivas escolas foram socializadas em um dos encontros do Grupo de Estudos e são essas questões que serão problematizadas neste trabalho.

\section{Acerca do Grupo de Estudos}

Antes de caracterizar o Grupo de Estudos, consideramos importante explicitar como acontece o processo de eleição do professor coordenador no contexto da referida Secretaria. O docente que tem intenção de se candidatar ao cargo de PC tem que apresentar, para a Secretaria de Educação, o plano de trabalho que irá desenvolver na escola onde pretende atuar. Uma vez aprovado nessa instância, o PC tem que apresentar a proposta na escola. 
Pode haver propostas de diferentes docentes que as fazem para ocupar a função na mesma escola, por isso são os professores que votam e escolhem a melhor proposta.

A Rede Municipal conta com 25 escolas de Ensino Fundamental e 34 professores coordenadores, já que as escolas com maior número de alunos ou que atendam a três períodos e/ou projetos especiais possuem dois ou três professores coordenadores. Todos foram convidados a participar do Grupo de Estudos e, como já referido, 32 professores coordenadores aceitaram o convite.

A proposta dos encontros era que os mesmos tivessem duração de duas horas, mas sempre ultrapassavam o tempo e a maioria dos participantes ficava até o final das discussões. Não houve ninguém apontando para a questão do avançar das horas; sempre era a CP que tinha que dizer: "Vamos encerrando, pois nosso tempo combinado já ultrapassou" (CADERNO DA COORDENADORA PEDAGÓGICA, 14/08/2014).

Quando a CP iniciou seu trabalho na coordenação pedagógica da Secretaria da Educação, não tinha clareza sobre o trabalho a ser desenvolvido. As reuniões com os professores coordenadores das escolas eram realizadas mensalmente, no entanto, com caráter informativo e com questões burocráticas sobre o que os professores coordenadores precisavam realizar junto aos pares, para que o trabalho atingisse os objetivos propostos por eles em cada escola.

A CP entendia que parte do seu trabalho era "apagar fogo" dentro das escolas, o que significava mediar conflitos gerados no cotidiano escolar com pais, professores, alunos, direção, quando das visitas realizadas por ela nas escolas. Porém, suas tarefas eram várias no contexto dessa Secretaria: oferecer formações aos PC; visitar as escolas auxiliando na elaboração de HTP (Horário de Trabalho Pedagógico); participar de formações fora do município e depois socializar esses estudos com os PCs; acompanhar o rendimento escolar dos alunos das 25 Unidades de Ensino Fundamental; orientar a aplicação de avaliações externas; buscar parcerias com outras Secretarias do município, visando a integração das atividades curriculares; atender aos pais quando estes buscam a Secretaria da Educação para orientações ou reclamações; atuar junto à supervisão escolar quando o assunto aborda questões de legislações e parceria com as demais coordenadorias do CAP (Educação Infantil, Educação Especial, Educação de Jovens e Adultos e Meio Ambiente).

Porém, a CP percebeu que seu trabalho não estava promovendo um processo de formação que atingisse todo o coletivo dos PCs que ela coordenava, segundo o previsto nas atribuições do CAP. Em função disso, surgiu a ideia de propor a todos eles a constituição de um Grupo de Estudos, que seria uma proposta diferenciada, uma vez que objetivava contribuir na constituição do professor coordenador frente às atribuições que lhe são apresentadas nos documentos legais.

Todos os encontros foram registrados pela CP num caderno que foi chamado de registro da coordenadora pedagógica. A primeira pauta de trabalho foi definida pela $\mathrm{CP}$, sendo que as demais foram pensadas ao final de cada encontro, com o grupo. Durante os encontros, eram socializadas experiências e propostas de ação nas escolas. Foram realizadas tanto leituras científicas como literárias, exibidos curtas e um clip musical. A proposta em 
trazer esses materiais diversificados tinha como pano de fundo alargar os horizontes para além de questões de compreensão de determinados conhecimentos, ampliando assim a percepção de mundo, sensibilizando o olhar e enriquecendo as discussões, ao possibilitar que a vida e os sentimentos pudessem circular na roda do grupo, criando o compartilhamento da palavra (CHALUH, 2012).

$\mathrm{Na}$ medida em que as discussões aconteciam, a CP percebeu que estava constituindo um espaço que, anteriormente, ela mesma não tinha promovido dentro da Secretaria Municipal da Educação. Ouvir o grupo manifestar seus desejos, anseios, opiniões foi o modo de compreender que a CP também estava em processo de formação. Ao ficar responsável pela coordenação desse grupo, ela percebeu que esse espaço também lhe possibilitaria repensar suas ações como formadora. O processo de formação era de mão dupla, tratava-se da formação dos PCs e da CP.

Uma prática instituída no grupo de estudo foi a sistematização de alguma tarefa que teria que ser compartilhada com o grupo no encontro seguinte. As tarefas eram pensadas pela $\mathrm{CP}$ e apresentadas aos participantes no final de cada encontro, definindo, coletivamente, a possibilidade ou não de realização das mesmas. Porém, nem sempre todos os PCs tomaram para si a escrita, nem a realização das tarefas. Questões que não serão discutidas neste trabalho, mas que indiciam a necessidade de repensar o sentido da formação e as concepções de formação dos PCs.

Outra prática instituída durante os encontros foi o convite por parte da CP às PCs para a elaboração de uma carta na qual registrassem de que forma suas ações nas escolas eram coerentes com as propostas e ações do Plano apresentado, por elas, quando se inscreveram para o processo de eleição na Unidade Escolar em que atuavam.

Alguns questionamentos realizados pela $\mathrm{CP}$ nos encontros do grupo foram: Em que momento decidiu ser professor coordenador? Como se constitui enquanto professor coordenador? O que o motivou a ser professor coordenador? Quais as atribuições que considera de sua competência?

Como já referido, uma das propostas feitas e que guarda relação com o foco deste trabalho foi que os PCs realizassem uma pesquisa com os professores das respectivas escolas para que eles registrassem por escrito e anonimamente a seguinte questão: "o que os professores esperam do professor coordenador" em relação a sua atuação e atribuições. No $3^{\circ}$ encontro, dos 22 professores coordenadores que estavam presentes, 17 levaram os registros dos professores das suas escolas. Ao solicitar que os PCs expusessem suas opiniões após a leitura das escritas dos seus professores, eis que vieram as falas:

Não gostei do que li;

Eu faço tudo o que relataram, mas não está bom;

Nunca estão contentes;

Pedem coisas que eu já faço;

Dizem que não dou atenção;

Que não fico na escola;

Fiquei decepcionada com meu grupo;

Meu grupo não escreveu nada; 
Só li mentiras;

Gostei muito;

Meu grupo me surpreendeu;

Recebi elogios e gostei muito. (CADERNO DA COORDENADORA PEDAGÓGICA, 07/10/2014).

O propósito desse primeiro momento foi entender as sensações dos PCs, alguns deles não compreendiam que os dizeres dos professores eram relacionados com a função e não com a pessoa do PC. Como mediadora, a CP tinha a intencionalidade de que os PCs olhassem para esses registros tendo uma atitude investigativa, na busca por compreender o que os professores entendiam acerca da função do $\mathrm{PC}$ e, a partir disto, poder repensar suas ações no contexto escolar.

Posteriormente, a CP solicitou que os PCs se organizassem em pequenos grupos e relatassem as escritas dos professores, falassem sobre os "absurdos" que alguns professores pontuaram.

$\mathrm{A} \mathrm{CP}$, atenta às falas dos $\mathrm{PCs}$, conseguiu fazer os seguintes registros no seu caderno:

Olha o professor pede que eu faça HTPC com mais leituras, mas isso eu realizo!

Que tenha um espaço para as trocas de experiência e quando eu deixo este espaço eles não fazem uso.

Estão me confundindo com psicólogo, pois dizem que tenho que ouvir o que têm para dizer (Caderno da Coordenadora Pedagógica, 07/10/2014).

Porém, após refletir coletivamente sobre as produções dos professores, ainda alguns PCs acreditavam que os escritos dos professores estavam direcionados à questão pessoal e não à sua função.

Um dos participantes lançou como proposta realizar a "leitura trocada", ou seja, um PC teria que ler as escritas do outro. A proposta foi aceita e os PCs se sentiram mais confortáveis nessa situação, segundo relato: "aqui não sou eu, mas sim minha função" (Relato de um PC, 07/10/2014).

$\mathrm{Na}$ ocasião, após as reflexões e discussões, os pequenos grupos sistematizaram o material produzido pelos professores em relação ao que esperam do PC. Segue a sistematização realizada:

- socializar na escola as formações do professor coordenador

- HTPC com atividades diversificadas

- desenvolver o democrático

- auxiliar no pedagógico (individual)

- mediador

- disponibilizar materiais nos HTP (Horário de Trabalho Pedagógico)

- orientar sala de aula

- organizar o trabalho pedagógico (coletivo)

- acompanhar os registros 
- cumprir objetivos estabelecidos no Plano do Professor Coordenador

- atendimento ao PEB II (Professor de Educação Básica - Especialistas)

- atendimento em HTPI

- trazer novos conhecimentos para o grupo

- formação em HTPC

- trocas de experiências

- ouvir os professores

- acompanhar rotinas

- sugestão de planejamento

- trabalho em equipe/parcerias

- promover atividade reflexiva do professor

- aceitar intervenções

- conhecer referenciais teóricos

- não se ausentar da escola.

- sensibilidade e respeito

- ser humanista

- escutar os professores nas angústias e diminuir ansiedade

- elogiar o trabalho realizado

- ter imparcialidade nos conhecimentos (não diferenciar professores em virtude de sua formação)

- garantir união/respeito/diálogo e sucesso no trabalho

- ética e amizade

- sentir ausência do professor coordenador na escola

- ser compreensivo

- estimular e incentivar

- polidez no tratamento individual (não fazer diferença entre os professores)

- ser parceiro

- solidão do professor (estar junto)

- desabafo

- paciência (CADERNO DA COORDENADORA PEDAGÓGICA, 07/10/2014).

A sistematização das considerações dos professores a partir da leitura e reflexão dos PCs nos permite apresentar algumas dimensões que podem ser contempladas ao pensarmos nas atribuições do PC. Ainda que essas dimensões estejam entrelaçadas, tentamos discriminar as mesmas para um melhor entendimento das questões postas pelos professores.

a) Do trabalho pedagógico. Percebemos indícios dessa dimensão quando os professores explicitam que os PCs têm que estar presentes, para potencializar o trabalho desenvolvido no Horário de Trabalho Pedagógico Coletivo e/ou Individual, ao orientar em sala de aula, ao acompanhar registros e rotinas;

b) Da formação. Nesta dimensão, surge a ideia de que os PCs se percebam como mediadores. Também suas atribuições estariam vinculadas a oportunizar trocas de experiências, socializar formações nas quais só o PC teve a oportunidade de participar, que divulguem novos conhecimentos e que tenham bagagem acerca de determinados referenciais teóricos;

c) Dos valores. Foram explicitadas características que o PC teria que ter nas relações com os outros: ouvir os professores e ter sensibilidade e respeito; elogiar, estimular e incen- 
tivar o trabalho dos professores; ser imparcial perante os acontecimentos; ser compreensivo; ter ética e polidez; estabelecer relações de amizade e mostrar sua humanidade.

d) Do coletivo. Foram expostos argumentos que legitimavam que os PCs têm que contribuir no desenvolvimento da democracia na escola, realizar trabalho em equipe, ser parceiro, garantir a união do grupo.

Para ampliar a compreensão do lugar do professor coordenador no contexto escolar, frente a estas quatro dimensões atreladas às atribuições do PC e que se depreendem das expectativas dos professores das escolas, na sequência, dialogamos com alguns autores que, com suas discussões, contemplam e ampliam a compreensão das dimensões elencadas.

\section{Dimensões DO TRABALHO DOS PROFESSORES COORDENADORES}

Nesta seção, discutimos sobre as quatro dimensões referidas articuladas com autores que têm problematizado o lugar do professor coordenador no contexto escolar.

No que se refere ao trabalho pedagógico, foi explicitada a necessidades de que os PCs têm que potencializar o trabalho desenvolvido no Horário de Trabalho Pedagógico Coletivo e/ou Individual, além de orientar o trabalho em sala de aula e acompanhar tanto registros como rotinas.

No decorrer dos encontros do Grupo de Estudos, os PCs pontuaram sobre a cobrança que os professores fazem quanto a sua atuação no que diz respeito ao comportamento e disciplina dos alunos. Seria esta uma atribuição do PC, embora possa ser compreendida e mesmo justificada pelos próprios professores quando apontam que a indisciplina dos alunos interfere na qualidade das aulas, e portanto, o PC necessita intervir junto aos mesmos. No entanto, nos documentos que descrevem as atuações do PC não há clareza quanto ser esta uma de suas atribuições. Assim, a dimensão relativa ao trabalho pedagógico está atrelada ao processo formativo dos professores para atuarem junto às questões da indisciplina, do que propriamente sua intervenção com os alunos.

Nesse sentido, dialogamos com Hobold (2012), que socializa uma pesquisa na qual discute e analisa o papel do coordenador pedagógico no processo de formação continuada dos professores de Educação Básica e na organização do trabalho pedagógico. Os participantes da pesquisa foram docentes e diretores de escolas. Os resultados apontaram que docentes e diretores atribuem um valor significativo ao trabalho do coordenador pedagógico, mas, ao mesmo tempo, não têm clara função deste profissional.

Os dados da pesquisa mostram a necessidade de estabelecer uma relação de interdependência entre os professores, coordenadores e direção para que ocorra o ensino e aprendizagem nos espaços escolares, no entanto, os resultados da mesma deixam em evidência que o PC desconhece o que se passa em sala de aula. Essa autora explicita que as atividades burocráticas que o PC realiza são compreendidas pelos participantes da pesquisa como atribuição da função do professor coordenador.

Trazemos este autor (HOBOLD, 2012), pois reconhece, a partir de sua pesquisa, uma questão posta pelos professores que disseram das atribuições do PC e que tem a ver com orientar em sala de aula, acompanhar registros e rotinas. Necessidade legítima já que tem, como pano de fundo, a aprendizagem das crianças, ao poder acompanhar o trabalho da 
sala de aula de cada professor. Reforça-se assim a ideia de que o trabalho pedagógico do PC também é atuar e acompanhar o desenvolvimento dos alunos. Compreendida aqui a dimensão pedagógica.

$\mathrm{Na}$ pesquisa realizada por Freitas (2012), evidencia-se a figura do professor coordenador no papel de formador docente, focando a implantação de políticas públicas promovidas pela Secretaria de Educação do Estado de São Paulo, após a constatação do desempenho insuficiente dos alunos. Assim, insere-se a figura do professor coordenador como apoio à implantação de um Programa de Formação, objetivando a gestão do currículo nas unidades escolares.

Há um modelo a ser seguido por todos os professores coordenadores, pois todos seguem os Cadernos de Gestores do Currículo. A metodologia adotada foi a pesquisa documental da Proposta Curricular do Estado de São Paulo, fundamentada em pesquisa bibliográfica pertinente à temática. Observou-se na pesquisa que o uso dos Cadernos (de professores e alunos) estimula o individualismo entre os pares, pois dispensa o diálogo para se discutir os afazeres docentes com relação ao conteúdo a ser ensinado. A utilização de tais Cadernos acaba sendo um poder controlador para todos, já que os professores não possuem liberdade para fazer o que querem. O mesmo ocorre com o professor coordenador em seu Caderno de Gestor. Há uma discussão em que o dominador não exclui o dominado, mas o incorpora como tal. O coordenador é visto como líder que irá conduzir a escola a todas as mudanças previstas. Ainda que a pesquisa traga o processo de implantação de um Programa de Formação, explicita uma preocupação com o desempenho dos alunos. Assim, mais uma vez, aparece a importância do trabalho do professor coordenador atrelado ao desempenho de alunos, a necessidade posta pelos professores, alguns citados neste trabalho, ou em maiores detalhe na dissertação, de que exista orientação em sala de aula. Outro autor que focou sua pesquisa na questão dos educandos e na formação dos professores tendo o PC como articulador das práticas foi Filho (2012). Na pesquisa, reconhece-se que a escola é um espaço de formação, mas criticam-se os modelos de formação, pois não dão conta de atender às reais necessidades de formação dos educandos. Mais um trabalho que discute a dimensão do trabalho pedagógico, deixando em evidência a necessidade do trabalho pedagógico do PC ter como foco a aprendizagem dos alunos.

Placco, Almeida e Souza (2015) apresentam a ideia relativa às atribuições do professor coordenador, ou melhor, sobre aquilo que compete ou não aos afazeres do professor coordenador. Há certa confusão quanto à compreensão do que de fato compete ao professor coordenador e ao diretor. Em pesquisa realizada em várias regiões do Brasil, as autoras constataram que alguns diretores atribuem aos professores coordenadores as funções administrativas e burocráticas da escola. Em outra região, exceto São Paulo, a função formativa não é atribuída ao professor coordenador, e os professores por sua vez atribuem ao professor coordenador funções de fiscalização.

Nesse sentido, a não definição das atribuições do professor coordenador reforça a ideia de que o coordenador seja o "solucionador de problemas, o bombeiro ou 'apagador de incêndios"” (PLACCO; ALMEIDA; SOUZA, 2015, p. 15).Assim, esta pesquisa afirma 
que seriam vários os afazeres e as tarefas que o PC terá que cumprir, sendo que o trabalho pedagógico seria mais um, e talvez, aquele específico da função do PC não seja legitimado no contexto da pesquisa realizada por estes autores, o que mostra a disparidade de entendimentos acerca dos trabalhos que são de responsabilidade específica do PC.

Geglio (2003) discute a contribuição do coordenador pedagógico na formação continuada do professor em serviço. Segundo ele, o acompanhamento pedagógico dos alunos também faz parte de suas atribuições. Para esse autor, o professor coordenador não deve realizar atividades burocráticas, pois, ao envolver-se com tais atividades, reduz o tempo destinado à formação continuada dos professores. Esse autor também apresenta a necessidade de olhar, como atribuição do PC, o acompanhamento pedagógico dos alunos, legitimando, assim, as considerações feitas pelos professores contemplados na pesquisa aqui apresentada.

Em relação à dimensão da formação, importa lembrar que, a partir das considerações dos professores foi possível identificar a necessidade de que os PCs se percebam como mediadores, sendo responsáveis por oportunizar trocas de experiências, socializar formações das quais apenas participaram os PCs, divulgar conhecimentos acerca de determinados referenciais teóricos.

No que se refere à formação, vincula-se ao professor coordenador atribuições que estão voltadas ao saber-fazer, sendo compreendido como um processo integrado à dinâmica do cotidiano escolar, associado ao ensino-aprendizagem, às relações e aos sujeitos escolares. Neste contexto, cabe ao professor coordenador certa postura articuladora, em que a escuta se faça presente.

Magalhães (2012) apresentou em sua pesquisa o quanto o saber-fazer do professor coordenador está vinculado às relações estabelecidas com seus pares. Entende-se que, quando o professor coordenador escuta seus professores, há um momento de trocas, sendo estes momentos reconhecidos como formação continuada além do fortalecimento das relações. Ao trazer este trabalho, apontamos a necessidade de pensar que a escola é um espaço de formação, onde o PC tem que perceber a importância de ser articulador desses processos. Acreditamos que o trabalho de Magalhães (2012) também nos leva a pensar na terceira dimensão constitutiva das atribuições do PC, dos valores, isto porque o autor enfatiza a importância da escuta nesses processos de formação.

Dutra e Rocha (2014) apresentam como tema central do artigo o questionamento de qual deve ser a atuação do coordenador pedagógico como formador de formadores, ressaltando-se a importância na formação contínua de professores. Para tanto, buscam respostas num Decreto que aborda a função do professor coordenador, constatando seu papel fundamental na formação docente. No entanto, a realidade não é esta dentro das escolas, pois encontramos professores com antigas práticas e sem um direcionador efetivo para mudanças em seu trabalho. Da pesquisa realizada pelas autoras depreende-se que os PCs passam muito tempo envolvidos com questões burocráticas e com o gerenciamento de problemas, e que gostariam de ter mais tempo para trabalharem com formação de professores.

Sem dúvida, a tarefa formadora, articuladora e transformadora é difícil, pois não há modelos prontos para serem seguidos. Cada formador precisa criar soluções adequadas 
à sua realidade. Frente a isso, as autoras realizaram um estudo de caso, no qual tiveram a oportunidade de conhecer um trabalho diferenciado de formação de professores realizado por uma PC.Assim, ainda sabendo das dificuldades para promover espaços de formação nas escolas, mais uma pesquisa indicia a importância do PC como articulador de processos formativos.

Assumir a função de coordenação da formação dos educadores de uma escola requer compreender seu papel, as características de sua função e atuação. Ainda há pouca clareza quanto ao que seria de fato papel do PC, confundindo, muitas vezes, com os papéis do diretor. Evidenciou-se também na pesquisa de Macedo (2014) a complexidade da atuação do PC, já que esta é caracterizada como múltipla e diversa, no entanto espera-se uma atuação ativa do PC. Há certa tendência em apontar o PC como o profissional habilitado a resolver os conflitos surgidos no cotidiano escolar. Embora alguns sejam da sua competência, a formação seria um espaço para trazer à discussão as diversas situações práticas que enfrentam nas escolas.

Retomando a pesquisa de Oliveira (2016), foco deste trabalho, colocou-se também na discussão o exercício das relações, inclusive as de poder. A pesquisa concluiu sobre a necessidade de aprimoramento constante para os PCs, já que durante as análises das respostas observou-se que houve pouca indicação de estudos teóricos, relacionando-os com o aprimoramento da prática da coordenação. Quanto aos PCs que, naquele momento do grupo de estudos, tinham iniciado recentemente sua atuação como professores coordenadores, estes apontaram para a importância de entrar em contato com diferentes experiências, realizando trocas de estratégias e práticas de trabalho. Neste trabalho aparece destaque especial para a própria formação do $\mathrm{PC}$, a necessidade de apreender como ser um articulador de processos formativos que lhe possibilite ter uma bagagem para poder coordenar estudos teóricos e discussões da prática pedagógica.

Pereira (2014) traz em seu trabalho um recorte da dissertação de mestrado, em que apresenta a escola como espaço de formação docente e desenvolvimento profissional e o coordenador pedagógico como responsável pela articulação da formação continuada no contexto do trabalho coletivo. Neste recorte, o autor apresentou as reflexões sobre as dificuldades do PC vinculadas a sua relação com os professores e direção.

Para que o PC possa desempenhar sua função de formador é necessário planejar e objetivar ações a serem realizadas nos espaços de formação de professores. No entanto, o trabalho do PC é marcado pela improvisação de ações, por situações inesperadas e imprevisíveis, acúmulos de tarefas, falta de tempo, desvio de função, atendimento de demandas urgentes, constantes interrupções e rotinas de trabalho burocratizadas.

Mais uma vez, outro estudo que legitima o lugar do PC como formador de professores, porém argumentando a imperiosa necessidade de ter um planejamento sobre os processos formativos que pretendem desenvolver, uma vez que, como já problematizado neste trabalho, com outros autores, o trabalho do PC está marcado também por situações inesperadas que o levam a sair de propostas que são fundamentais, se pensarmos na aprendizagem dos alunos.

Acerca da dimensão dos valores, retomamos aqui a importância de ouvir os professores e serem compreensivos; de ter sensibilidade e respeito, estabelecendo relações de 
amizade; de elogiar, estimular e incentivar o trabalho dos professores; de ser imparcial perante os acontecimentos.

Placco (2012) explicita no seu texto o tempo que o coordenador pedagógico ocupa para apagar incêndios nas escolas, tirando preciosos momentos para que ele promova a construção e reconstrução do cotidiano coletivamente, para assim atender ao Projeto Político Pedagógico. A autora reforça que uma função fundamental do coordenador pedagógico é cuidar da formação e do desenvolvimento profissional dos professores. Promove uma reflexão naquilo que ela chama de nossos mundos internos, do ponto de vista de valores, atitudes e, principalmente, de ampliação de consciência com tudo o que se tem feito no cotidiano escolar: modo de conduzi-lo, controle da docência, a atuação dos docentes nos Conselhos de Classe, as avaliações realizadas, estudos realizados, a formação dos profissionais, a compreensão das teorias, e suas aplicações na prática. Assim, o que a autora chama de mundos internos passa a ser compreendido como o aparecimento de contradições entre aquilo que é proposto como fundamento teórico e a prática cotidiana das escolas, sendo que o que deve gerar questionamentos nos valores e crenças dos professores deve gerar dúvidas em suas certezas, tarefa esta que compete ao coordenador pedagógico.

São poucos os trabalhos que abordam a questão dos valores, sendo que estes são compreendidos como sentimentos, como forma de respeito ao trabalho realizado pelos docentes, relações de amizade e incentivo ao saber-fazer e, ainda, a questão do reconhecimento docente pensando na questão salarial. No entanto, o que de fato podemos entender sobre os valores apresentados pelos PCs que participaram da pesquisa em questão? Não daremos conta neste artigo de abordar sobre os baixos salários que tanto incomodam os profissionais da educação, mas sim pensar nestes valores como algo que humaniza o trabalho em questão.

Por último, tratamos da dimensão do coletivo, lembrando que esta questão legitimava que os PCs são responsáveis por potencializar a vida democrática na escola, promover o desenvolvimento de trabalhos em equipe na busca da união do grupo em função de um objetivo.

Placco e Souza (2008) apresentam a possibilidade de reflexão sobre o trabalho coletivo na escola como ação preventiva, que pode ser entendida como relação dialógica entre o educador e a criança. Quando se trabalha com a prevenção, há redução de danos na formação e no desenvolvimento das crianças. Cabe ao coordenador assim atuar junto à formação dos professores, mas para isso é necessário um projeto de escola onde todos possam estar envolvidos. A questão principal do texto é: como atuar de maneira a minimizar os efeitos de situações conflituosas e complexas que envolvem alunos e professores ou gestores? Apresenta-se uma discussão em que a equipe gestora, compreendida como direção, vice e coordenação, trabalhem em parceria visando articular o grupo de professores para que e cada um dos envolvidos se mobilize e se comprometa com o trabalho pedagógico da escola.

Para que isso ocorra, há necessidade de formação e desenvolvimento profissional dos professores, não apenas individual, mas formação mútua (interformação) e autoformação. As transformações acontecerão na medida em que o professor fizer reflexões sobre sua própria prática docente, tendo como referência o Projeto Político Pedagógico da escola. 
Esse é um processo individual e coletivo, complexo e dinâmico, que necessita de ajuda dos gestores, de forma que os professores identifiquem seus sentimentos, desejos, motivações, competências, sentidos e significados de seu pensar e fazer pedagógico, sendo autores de sua prática. Assim, o trabalho coletivo é construído pelo educador e promovido pelo coordenador, responsável pela mediação desse processo.

As transformações que os autores acima apresentam só serão possíveis na medida em que pensarmos o coletivo, vivenciarmos o coletivo, nos formarmos com e no coletivo, e entendermos que ações isoladas pouco contribuem para amenizar os diversos desafios presentes no espaço escolar.

Reafirmando a ideia da necessidade do trabalho coletivo, Chaluh (2008) chama a atenção para a questão do sujeito coletivo, como instância possibilitadora de resolução dos conflitos, pois:

[...] no momento em que deixamos de olhar para nós mesmos, sujeitos individuais, conseguimos nos enxergar na relação com os outros sujeitos, com os quais compartilhamos essa contradição, na busca de saídas que permitam resolver os conflitos vividos por todos (CHALUH, 2008, p. 120).

Nóvoa (1999) adverte quanto ao empobrecimento das práticas associativas, cuja carência tem consequências negativas na profissão docente. Assim, afirma que:

É urgente, por isso, descobrir novos sentidos para a ideia de coletivo profissional. É preciso inscrever rotinas de funcionamento, modos de decisão e práticas pedagógicas que apelem à co-responsabilização e à partilha entre os colegas. É fundamental encontrar espaços de debate, de planificação e de análise, que acentuem a troca e a colaboração entre os professores (NÓVOA, 1999, p.16).

Nóvoa nos convida a pensar na necessidade de co-responsabilizarmos pela construção da escola, na partilha, no debate, na troca, na colaboração. Nesse sentido, não há como desconsiderar a importância do diálogo, para que esses movimentos possam de fato acontecer.

De outra perspectiva, Chaluh (2012), ao argumentar acerca da coletividade, explicita que a mesma pode se constituir quando um grupo passa a ter consciência das necessidades e situações-problema e, por sua vez, vai em busca de alternativas para avançar, promovendo ações para resolver os conflitos, de forma que os sujeitos assumam responsabilidades perante as suas ações. Segundo a autora,

Ao discutir a constituição da coletividade, para desenvolver um trabalho coletivo, faz-se necessário tomar consciência dos problemas e em forma conjunta enunciar uma ação e concretizar essa ação na prática. Nesse sentido, não basta tomar consciência dos problemas e ou dificuldades, é preciso enunciar! É preciso dizer, é preciso se colocar, é preciso assumir um lugar na escola e na educação (CHALUH, 2012, p. 13). 
Assumir um lugar na escola e no mundo, sendo co-responsáveis pelas ações definidas na coletividade, implica admitir os conflitos. Conflitos que só podem surgir quando existe espaço para que a palavra dos sujeitos que fazem a escola possa circular. As professoras das escolas explicitaram a necessidade de viver democraticamente, viver em união. Isto implica o reconhecimento do outro, que é diferente de mim, porém com quem posso ser co-responsável pela construção da escola. Viver em comunidade e definir coletivamente ações não implica o apagamento das diferenças.

O que muito acentua a ideia da dimensão do coletivo é o pensamento de se colocar no lugar do outro, ocupar este lugar para dialogar e tomar juntos decisões.

Pensando neste exercício do onde o eu e o outro se fazem presentes, dialogamos com Miotello e Moura (2012) autores que afirmam que:

constituição do Eu sempre é concessão do outro. A iniciativa do diálogo é sempre do outro. E eu vou me constituindo nos limites entre eu e o outro, vou existindo pelas ofertas do Outro. Nesse jogo a minha identidade é uma atividade coletiva, cujo ponto de partida é sempre o outro (p. 555).

Os referidos autores, a partir de uma perspectiva bakhtiniana, deixam explícita que a nossa constituição se dá na alteridade, com o outro, no coletivo, a partir do outro.

Até aqui, problematizamos as atribuições dos PCs pelo olhar das professoras das respectivas escolas. A seguir, problematizamos o olhar da CP perante algumas situações vividas com os PCs e que tem a ver com a construção de valores, de processos formativos e de relações interpessoais.

\section{As LIÇÕES APRENDIDAS COM A PESQUISA}

Como já referido, a CP assumiu uma pesquisa narrativa (LIMA, GERALDI; GERALDI, 2015), na qual o investigador se distancia da própria história para dialogar o tema com outros textos, outras vozes. Por meio da pesquisa narrativa, a CP teve a oportunidade de tomar consciência dos princípios que guiaram seu trabalho, ou seja, foi preciso ter clareza a respeito do que estava fazendo, quanto do porquê e para que estava fazendo. Ao narrar os fatos, a CP pode colocar suas incertezas, seus receios e inquietações e, assim, ver no outro o quanto tudo isso também fazia presente. Por meio da investigação narrativa é possível realizar uma prática reflexiva, visando romper as práticas rotineiras. Tal forma de pesquisa surgiu em virtude da insatisfação com as produções de campo na área da educação, que se caracterizam por falar sobre a escola, em vez de falar com ela e a partir dela (LIMA; GERALDI; GERALDI, 2015).

Essa perspectiva de pesquisa está voltada para os sujeitos que fazem a escola, pois as contribuições dessas pesquisas embasam os processos de formação e incidem sobre os principais interessados. Com o intuito de explorar e aprimorar os aspectos de sua prática, os professores têm sido convidados, nos programas de formação continuada, a refletirem so- 
bre suas próprias práticas educativas. No entanto, como aponta Zeichner (1993), a reflexão sobre a própria prática não é um processo espontâneo do profissional da educação isolado na rotina escolar.

Fazer pesquisa narrativa pode ser compreendido como uma forma de registrar os acontecimentos, ou melhor, participar da construção da história, que nesse caso envolve a construção histórica do processo de formação entre professores coordenadores e coordenadora pedagógica. Nossas experiências nem sempre são registradas e, assim, nossa história pode ser perdida, ficar na memória apenas de alguns ou mesmo ser dissolvida frente à rotina de trabalho que o universo escolar nos apresenta cotidianamente.

Ao realizar pesquisa narrativa, podemos dizer que passamos por um processo de investigação, em que o vivido passa a ser questionado, há dúvidas de onde buscar os referenciais metodológicos, como se dá a coleta dos dados. Tudo isso não é tarefa simples, pois tomamos o objeto de estudo para nós e passamos a ser o protagonista da pesquisa. Não há um método definido que possa reger cientificamente tal pesquisa, no entanto, não pode deixar de ser considerada pesquisa, pois há uma linha de raciocínio a ser seguida, um objeto a ser estudado, exige do pesquisador o pensar frente à complexidade dos acontecimentos vividos. Deve-se tomar cuidado com esse tipo de pesquisa, para que não seja compreendido como uma mera contação de histórias. Não há receitas prontas e seguras para realizá-la.

O trabalho com a narrativa trouxe para a $\mathrm{CP}$ a oportunidade de revisitar sua atuação como coordenadora pedagógica. Trabalhar com a pesquisa narrativa fez a CP viajar para o lugar de onde partiu para analisar seu processo de formação e, retornando ao presente, mudar o rumo da sua trajetória. A pesquisa narrativa lhe trouxe lições, aprendizados.

Durante os encontros do Grupo de Estudos, a CP percebeu um gradativo crescimento da confiança entre os professores coordenadores e com ela, enquanto coordenadora pedagógica, o que deixou o grupo mais próximo, a ponto de revelar a necessidade de revisitar a atuação deles enquanto coordenadores. A CP também entendeu que estava na condição de repensar toda sua atuação e formação no contexto no qual estava inserida, a Secretaria Municipal da Educação. A confiança é um aprendizado que explicita um valor fundante, ao pensarmos a constituição de grupos.

A questão do silêncio percorreu grande parte dos encontros do Grupo de Estudo. A $\mathrm{CP}$ compreendeu que esse silêncio indiciava uma concepção de formação, uma concepção de "receber" a formação, como se esses sujeitos nada tivessem a dizer. Atenta ao silêncio, a CP se propôs a promover ações que levassem esses sujeitos a vivenciar de outra forma seus processos formativos, promovendo situações onde a palavra pudesse circular e, assim, compartilhar experiências e ampliar os horizontes acerca do que se compreendia nesse contexto em relação ao que é ser um professor coordenador e suas atribuições.

Dialogamos com Nóvoa (1995), que argumenta contra certas propostas que se dizem formativas. São propostas que acreditam que a formação se dá por acumulação de cursos e mais cursos ou buscando técnicas de trabalho, que os professores chamam de "receitas prontas". Não são estas as propostas que o autor considera formativas. A formação se dá 
por meio de um trabalho de reflexividade crítica sobre as práticas e de (re)construção permanente do fazer pedagógico.

Na mesma linha, Imbernón (2009) explicita que o formador deve assumir um papel de colaborador, de parceiro, diante de um modelo de formação mais reflexivo, onde sejam oportunizados espaços nos quais seja possível analisar os obstáculos, tanto individuais, quanto coletivos, visando à elaboração de projetos formativos que os ajudem a avançar perante os conflitos. Evidencia-se, assim, um processo de formação continuada que potencializa a busca por mudanças na prática educativa, procurando meios para enfrentar os desafios presentes no contexto escolar.

Assim, o silêncio mostrou para a CP a necessidade de que os próprios PCs refletissem sobre as suas concepções de formação, pensando nas implicações das mesmas com o trabalho pedagógico proposto nas respectivas escolas.

Uma questão central para a CP foi compreender a importância das relações interpessoais, questão fundamental ao se pensar no trabalho, tanto dos PCs, quanto do CP. Foi possível compreender que as relações interpessoais estão diretamente atreladas ao processo de formação, pois não é possível desenvolver processos formativos, quando os sujeitos envolvidos nesses processos não possuem um bom relacionamento e não se envolvem nos mesmos. Relações estas não compreendidas como "coleguismo", em que nada se cobra do outro, pois "somos amigos", mas sim uma relação na qual um aprende com o outro, em que o profissionalismo, a responsabilidade e o compromisso se façam presentes.Nesse sentido, surge a necessidade de pensar em relações interpessoais sustentadas por no logro de objetivos comuns.

A CP percebeu que existe uma forte tendência em compreender que formações pontuais dão conta de atender aos anseios e necessidades de uma rede toda, e que um "formador-solucionador" irá trazer as receitas para os problemas do contexto escolar.

Ficou evidente nos encontros do Grupo de Estudos que alguns professores coordenadores esperavam modelos prontos para serem aplicados em suas escolas, visando solucionar os entraves apresentados pelos professores. No entanto, nas discussões do Grupo de Estudos, muitos professores coordenadores pontuaram que não há modelos prontos capazes de atender aos inúmeros desafios presentes no cotidiano escolar. Assim, as propostas de formação oferecidas, muitas vezes, não dão conta de atender aos anseios do professorado diante das especificidades apresentadas por eles.

Trazemos mais uma vez as considerações de Imbernón (2009), que explicita a necessidade de renovar a visão sobre formação, ou seja, transmitir ou ensinar não é sinônimo de compartilhar, atualizar não é o mesmo que analisar e tampouco aceitar significa refletir. Realizar formação não significa trazer a discussão da teoria e da prática do formador, mas sim ajudar a descobrir as teorias e as práticas implícitas nas práticas dos docentes. O processo de formação move-se sempre entre o aprender e o desaprender. Para que isso possa ocorrer, faz-se necessário, segundo a CP, mudar as propostas de formação que existem na rede de ensino: ser convidado a participar de uma formação, receber sugestões de práticas, realizar as mesmas no interior das escolas e depois voltar na formação com devolutivas do 
que deu certo ou não. São práticas pontuais que não contemplam a todos, se pensarmos em problemáticas individuais. Faz-se necessário trazer modelos mais indagativos, em que os professores coordenadores sejam convidados a assumir seus papéis formativos, nos quais possam planejar, executar e avaliar sua própria formação e a formação que propõem nos contextos nos quais estão inseridos.

\section{CONSIDERaÇões Finais}

O presente trabalho teve a intencionalidade de pensar a atuação dos PCs sob o olhar dos professores das escolas nas quais eles trabalham. Foi possível compreender suas atribuições a partir de quatro dimensões que se entrelaçam: trabalho pedagógico, formação, valores e trabalho coletivo.

Argumentamos que a dimensão dos valores foi uma questão central posta pelos professores e que dizem de características que o PC teria que ter para qualificar seu trabalho. Isto porque acreditamos que guarda relação com a necessidade de estarmos atentos ao outro, a todos os outros que estão na escola. Catani (2006, p. 85) nos instiga a pensar nesses outros nos processos formativos: "[...] sabemos como favorecer na formação de professores a compreensão e a análise dos seus próprios modos de estar atentos a si e aos outros?”.

Também apresentamos as lições apreendidas pela CP após ter desenvolvido a pesquisa com os PCs. Podemos dizer que as lições deixaram em evidência a concepção de formação que circulava tanto naquele Grupo de Estudos, como no contexto da mesma rede. $\mathrm{O}$ silêncio foi um importante indício que levou a $\mathrm{CP}$ a problematizar que formação é essa na qual os PCs acreditam e que desenvolvem no contexto de suas respectivas escolas.

Dialogamos com autores preocupados com os processos formativos, afirmando com eles a necessidade de contemplar aspectos individuais e coletivos e, fundamentalmente apostar em uma concepção de formação atrelada à ideia de partilha, de reflexão, da co-responsabilização, de assumir um compromisso por um objetivo comum. Uma formação que contraria a ideia de formação como treinamento ou da busca de uma formação para solucionar problemas. Argumentamos acerca de uma concepção de formação, sustentada em relações interpessoais de confiança, de compromisso, de atenção ao outro, uma formação singular, porque proposta no contexto de uma escola singular.

$\mathrm{O}$ conhecimento produzido na referida pesquisa permitiu à $\mathrm{CP}$ tomar consciência de que os problemas são muitos, além de complexos e interligados. O investigador se distancia da própria história para dialogar o tema com outros textos, outras vozes. A pesquisa foi realizada pela $\mathrm{CP}$ dialogando com os professores coordenadores e com os autores apresentados.

Como já referido, as lições são os aprendizados que surgiram a partir de determinados acontecimentos que mobilizaram a $\mathrm{CP}$, em específico aqueles que a fizeram repensar sua prática e sua concepção de formação, ou seja, os próprios PC. São lições que poderão contribuir para outros pesquisadores que desejam olhar para sua própria prática. 
Foi fundamental para a CP compreender que a ela foi possível formar e ser formada a partir do diálogo com o outro, estar com o outro e depois voltar a si mesma fazendo total diferença frente ao lugar que ocupava. Pensar que estes outros que estiveram e ainda poderão estar consigo neste processo de (re)construção de sua própria formação fizeram a $\mathrm{CP}$ repensar consideravelmente o lugar privilegiado que ocupou na SME.

Enquanto formadora, a CP buscou dialogar com Imbernón (2009), visando ampliar sua concepção de formação e assim compreender, que pouco a pouco, o formador deve assumir um papel de colaborador diante de um modelo de formação mais reflexivo, onde seja fundamental oportunizar espaços de inovação, cujo objetivo é analisar os obstáculos tanto individuais quanto coletivos, elencados pelos professores coordenadores visando a elaboração de projetos formativos que os ajudem a avançar diante os desafios. Nesta proposta de formação o formador passa a pensar junto, estabelece uma parceria com os professores, e não propõem ações entendendo ser solucionadora dos problemas. Evidencia-se assim um processo de formação continuada, pois sua prática educativa só será modificada quando encontrar meios para enfrentar os desafios presentes no espaço escolar.

No contexto da referida rede, cabe tanto aos $\mathrm{PCs}$ como à $\mathrm{CP}$, legítimos formadores de professores, repensar a relação com os outros e, com isso, a capacidade de escutar, observar e refletir juntos e, assim, terem a possibilidade de ampliar os horizontes de compreensão de si, dos outros e da escola. Trata-se de um movimento que requer mudanças na forma de compreender o processo de aprendizagem; é preciso vivenciar a capacidade de aprender com os outros.

Talvez conceber um processo de formação nos termos tratados neste texto, digam da necessidade de aceitar nossa incompletude. Freire (2015) nos lembra que somos sujeitos inconclusos e inacabados. Por isso, ainda temos a oportunidade de revisitar nossa formação, colocar em dúvida nossas crenças e concepções e tentarmos principiar nosso olhar para outra direção, a fim de objetivarmos mudanças na forma de conceber o ensino e a formação continuada.

\section{REFERÊNCIAS}

BENJAMIN, W. O narrador: considerações sobre a obra de Nikolai Leskov. In: Magia e técnica, arte e política: Ensaios sobre literatura e história da cultura. São Paulo: Brasiliense, 1985 (Obras escolhidas, vol.I).

CATANI, D. B. A autobiografia como saber e a educação como invenção de si. In: SOUZA, E. C. de; ABRAHÃO, M. H. M. B. (Orgs.). Tempos, narrativas e fiç̧ões: a invenção de si. Porto Alegre: EDIPUCRS, 2006.

CHALUH, L. N. Formação de professoras e trabalho coletivo no cotidiano escolar. In: Congresso Internacional Cotidiano Diálogos sobre Diálogos, 2012, Niterói. Anais[...]. Niterói: Universidade Federal Fluminense - Faculdade de Educação, 2012. 
CHALUH, L. N. Formação e alteridade: pesquisa na e com a escola. Tese (Doutorado em Educação) - Faculdade de Educação, Universidade Estadual de Campinas, Campinas, 2008 .

DUTRA, P. P.; ROCHA, M. S. P. de M. L. Coordenação Pedagógica e formação de professores: o papel da afetividade na construção do trabalho coletivo. In: XII Congresso Estadual Paulista sobre Formação de Educadores e II Congresso Nacional de Formação de Professores, 2014, Águas de Lindóia. Anais [...]. Águas de Lindóia, 2014.

FILHO, J.R. da S. Repensando a prática da coordenação pedagógica e dos professores na escola de ensino fundamental: contributos da formação contínua através da pesquisa-ação. In: XVI ENDIPE - Encontro Nacional de Didática e Práticas de Ensino, 2012, Campinas. Anais [...]. Campinas: Universidade Estadual de Campinas, 2012.

FREIRE, P. Pedagogia da autonomia: saberes necessários à prática educativa. Rio de Janeiro: Paz e Terra, 2015.

FREITAS, S. A. O professor coordenador, pilar estruturante da proposta curricular do estado de São Paulo (Gestão 2007-2010). In: XVI ENDIPE - Encontro Nacional de Didática e Práticas de Ensino, 2012. Anais [...]. Campinas, Universidade Estadual de Campinas, 2012.

GEGLIO, P. C. O papel do coordenador pedagógico na formação do professor em serviço. In: ALMEIDA, L. R. de; PLACCO, V. M. N. de S. (Org.). O Coordenador Pedagógico e o Cotidiano da Escola. São Paulo: Loyola, 2003. p.113-119.

GINZBURG, C. Sinais. Raízes de um paradigma indiciário. In: Mitos, emblemas, sinais. São Paulo: Companhia das Letras, 1989. p. 143-179.

HOBOLD, M. de S. A implicação do trabalho do Coordenador Pedagógico na formação continuada do professor. In: XVI ENDIPE - Encontro Nacional de Didática e Práticas de Ensino, 2012, Campinas. Anais [...]. Campinas: Universidade Estadual de Campinas, 2012.

IMBERNÓN, F. Formação permanente do professorado: novas tendências. São Paulo: Cortez, 2009.

LIMA, M. E. C. de C.; GERALDI, C. M. G.; GERALDI, J. W. O trabalho com narrativas na investigação em educação. Educação em Revista, Belo Horizonte, v. 31, n. 01, p. 17 44, Janeiro-Março 2015. 
MACEDO, S. R. B. A contribuição da formação continuada do coordenador pedagógico da educação infantil para sua atuação profissional. In: XII Congresso Estadual Paulista sobre Formação de Educadores e II Congresso Nacional de Formação de Professores. Águas de Lindóia. Anais [...]. Águas de Lindóia, 2014.

MAGALHÃES, P. M. M. de S. Entre perguntas e respostas: forma(ação), media(ação) e o saber-fazer do coordenador pedagógico. In: XVI ENDIPE - Encontro Nacional de Didática e Práticas de Ensino. Campinas. Anais [...]. Campinas, 2012.

MiOTELlo, V.; MOURA, M. I. de. Alargando os limites da identidade. In: IV Círculo - Rodas de Conversa bakhtiniana: nosso ato responsável. São Carlos: Pedro \& João Editores, 2012.

NÓVOA, A. Os professores na Virada do Milênio: do excesso dos discursos à pobreza das práticas. Educação e Pesquisa. São Paulo, v. 25, n.1, p. 11-20, jan./jun. 1999.

NÓVOA, A. Os professores e a sua formação. Publicações Dom Quixote. Instituto de Inovação Educacional. Lisboa, 1995.

OLIVEIRA, L. A. de. A ação profissional do coordenador pedagógico e do professor coordenador: proposições como formadores. Dissertação de Mestrado. Universidade Estadual Paulista, Instituto de Biociências de Rio Claro, 2016.

PEREIRA, A. G. As dificuldades dos coordenadores pedagógicos frente ao trabalho coletivo e a formação centrada na escola. XII Congresso Estadual Paulista sobre Formação de Educadores e II Congresso Nacional de Formação de Professores. Águas de Lindóia - SP, abril de 2014.

PLACCO, V. M. N. de S.; ALMEIDA, L. R. de; SOUZA, V. L. T. de. Retrato do coordenador pedagógico brasileiro: nuanças das funções articuladoras e transformadoras. In: PLACCO, V. M. N. de S.; ALMEIDA, L. R. de (Orgs.). O coordenador pedagógico no espaço escolar: articulador, formador e transformador. São Paulo: Edições Loyola, 2015.

PLACCO, V. M. N. de S.; SOUZA, V. L. T.Desafios ao coordenador pedagógico no trabalho coletivo da escola: intervenção ou prevenção? In: ALMEIDA, L. R. de; PLACCO, V. M. N. de S. (Orgs.). O coordenador pedagógico e os desafios da educação. São Paulo: Loyola, 2008.

PLACCO, V. M. N. de S.O coordenador pedagógico no confronto com o cotidiano da escola. In: ALMEIDA, L. R. de; PLACCO, V. M. N. de S. (Orgs). O coordenador pedagógico e o cotidiano da escola. São Paulo: Edições Loyola, 2012. 
RIO CLARO. Lei $\mathbf{n}^{\mathbf{0}}$ 3706, de 17 de novembro de 2006. Dispõe sobre a regulamentação do Centro de Aperfeiçoamento Pedagógico criado nos termos do Art. 262 da Lei Orgânica do Município e dá outras providências. Prefeitura Municipal de Rio Claro/SP.

ZEICHENER, K.M. A formação reflexiva de professores: ideias e práticas. Lisboa: Educa, 1993.

\section{Dados das AUtoras}

\section{Luciane Aparecida de Oliveira}

Professora do Departamento de Educação e do Programa de Pós-Graduação em Educação do Instituto de Biociências da Universidade Estadual Paulista "Júlio de Mesquita. Rio Claro/SP - Brasil. oliluci@bol.com.br

\section{Laura Noemi Chaluh}

Mestre em Educação pela Universidade Estadual Paulista “Júlio de Mesquita”. Rio Claro/ SP - Brasil. Vice-diretora da Secretaria Municipal de Educação da Prefeitura de Rio Claro, Rio Claro/SP- Brasil. lchaluh@rc.unesp.br

Submetido em: 10-7-2018

Aceito em: 26-6-2019 